\title{
Nefritis tubulointersticial aguda asociada a consumo de Anisakis en paciente alérgica
}

\author{
Alejandro Tomás-Latorre ${ }^{1 *}$, José M. Peña-Porta ${ }^{1}$, Manuel Moros-García², Carlo Bruno-Marta², \\ María P. Martín-Azara ${ }^{1}$, Hilda Villafuerte-Ledesma ${ }^{1}$, Ana Coscojuela-Otto ${ }^{1}$, Almudena Castellano-Calvo ${ }^{1}$ y \\ Rafael Álvarez-Lipe ${ }^{1}$ \\ ${ }^{1}$ Servicio de Nefrología; ${ }^{2}$ Servicio de Anatomía Patológica. Hospital Clínico Universitario Lozano Blesa, Zaragoza, España
}

\section{Resumen}

Presentamos el caso de una paciente de 70 años, con el único antecedente médico de interés de anafilaxia por Anisakis, que presenta un fracaso renal agudo con biopsia compatible con nefritis tubulointersticial de etiología alérgica tras la ingesta de pescado. A pesar de que no se ha publicado ningún caso previo de nefritis por hipersensibilidad a Anisakis, la clínica, evolución y biopsia fueron compatibles con esta sospecha, sin poderse encontrar otra posible etiología del fracaso renal agudo.

Palabras clave: Nefritis. Anisakis. Hipersensibilidad. Fracaso renal agudo.

\section{Acute tubulointerstitial nephritis associated with consumption of Anisakis in an allergic patient}

\section{Abstract}

We present the case of a 70-year-old patient with a unique interesting medical history of Anaphylaxis of Anisakis, who presents an acute renal failure with a biopsy compatible with tubulointerstitial nephritis of allergic etiology after fish intake. Despite the fact that no previous case of hypersensitivity nephritis to Anisakis has been published, the clinic, evolution and biopsy were compatible with this suspicion, without being able to find another possible etiology of acute renal failure.

Key words: Nephritis. Anisakis. Hipersensitivity. Acute renal failure.

\section{Introducción}

El Anisakis es un nematodo presente en pescados crudos de agua salada ${ }^{1}$, que pasa a infectar al ser humano tras el consumo de pescado contaminado. La anisakiasis ha presentado un aumento en su incidencia por el consumo de pescado crudo. En España, se relaciona especialmente con el consumo de boquerones y anchoas $^{2}$. La infección por este nematodo, que suele producir alteraciones gástricas, se ha relacionado también con cuadros de hipersensibilidad gastroalérgicos 0 IgE mediados ${ }^{1,2}$. La anisakiasis intestinal cursa con síntomas inespecíficos gastrointestinales, como náuseas,
Correspondencia:

*Alejandro Tomás-Latorre

E-mail: altola_tl@ hotmail.com
Fecha de recepción: 15-02-2020

Fecha de aceptación: 13-05-2020

DOI: 10.24875/NEFRO.20000003
Disponible en internet: 17-12-2020

Nefro Latinoam. 2020;17:108-112 www.nefrologialatinoamericana.com

2444-9032/○ 2020 Sociedad Latinoamericana de Nefrología e Hipertensión. Publicado por Permanyer. Este es un artículo open access bajo la licencia CC BY-NC-ND (http://creativecommons.org/licenses/by-nc-nd/4.0/). 
vómitos o diarrea, dentro de los 5 días después del consumo de pescado, que tardaría más en la infección intestinal $^{3}$. Por su parte, las reacciones alérgicas tienen un amplio espectro de presentación clínica, que varían desde urticaria hasta shock anafiláctico ${ }^{3}$.

\section{Material y métodos}

Presentamos el caso de una paciente, mujer, de 70 años y raza caucásica, que como únicos antecedentes médico-quirúrgicos de interés presentaba alergia a Anisakis y cirugía de cataratas en el ojo izquierdo hacía 3 años. La paciente no usaba tratamiento farmacológico de forma crónica. La alergia a Anisakis había sido diagnosticada hacía 9 años tras padecer una anafilaxia tras el consumo de boquerones en escabeche de elaboración casera.

Esta paciente presenta, tras el consumo de bacalao fresco, un cuadro de inicio insidioso de 2 semanas de evolución, que se inicia en diciembre de 2017 y consiste en clínica de astenia, dispepsia, anorexia y epigastralgia, sin fiebre, por lo que consulta con su médico de atención primaria. Se realiza una analítica sanguínea, que muestra una creatinina de $1.9 \mathrm{mg} / \mathrm{dl}$ (Filtrado Glomerular estimado por la fórmula Chronic Kidney Disease Epidemiology Collaboration [FGCKD-EPI] $25.84 \mathrm{ml} / \mathrm{min}$ ). En la analítica previa, de 3 años antes, la creatinina era de $0.74 \mathrm{mg} / \mathrm{dl}$. Ante estos hallazgos, es derivada a consultas de nefrología.

Una semana después, la paciente presenta un episodio sincopal de semiología vasovagal, por lo que acude al servicio de urgencias, donde se detecta un empeoramiento de la creatinina, que es de $2.85 \mathrm{mg} / \mathrm{dl}$, por lo que se adelanta la cita con nuestro servicio, que ve a la paciente 10 días después en consulta. En estos momentos presenta una creatinina de $4.67 \mathrm{mg} / \mathrm{dl}$, por lo que se decide el ingreso de la paciente.

Durante el ingreso hospitalario no se identificó otra posible noxa etiológica del cuadro renal además del antecedente de consumo de pescado fresco en paciente alérgica.

En cuanto a los resultados de bioquímica iniciales, además de una creatinina de $4.67 \mathrm{mg} / \mathrm{dl}$, destacó urea $1.15 \mathrm{~g} / \mathrm{l}$, albúmina $2.96 \mathrm{~g} / \mathrm{dl}$, PTH (paratohormona) 215 $\mathrm{pg} / \mathrm{ml}$ y una gasometría compatible con acidosis metabólica con anión GAP elevado (19 mmol/l), normoclorémica, $\mathrm{pH} 7.25, \mathrm{pCO}_{2} 36 \mathrm{mmHg}$, bicarbonato $15 \mathrm{mmol} / \mathrm{l}$. El hemograma no presentaba alteraciones reseñables.

\section{Otras pruebas complementarias}

Se descartó gammapatía después de la valoración por el servicio de hematología de nuestro hospital tras realizar inmunofijación en sangre y orina.
En la ecografía abdominal de la paciente, destacaban quistes sinusales renales bilaterales, sin otras alteraciones de interés.

El estudio de inmunología y serologías incluyó ANA (anticuerpos antinucleares), AMA (anticuerpos antimitocondriales), anticuerpos anti-células parietales, anti-músculo liso, antitransglutaminasa, anticardiolipina, ANCA (anticuerpos anti-citoplasma de neutrófilo), factor reumatoide, inmunocomplejos circulantes, complemento, inmunoglobulinas, $\mathrm{VIH}$, virus de la hepatitis $\mathrm{C}$, virus de la hepatitis B y anticuerpos frente Anisakis. Todos estos parámetros fueron negativos, excepto la determinación de IgE específica para Anisakis, que fue positiva a títulos de $2.16 \mathrm{KU} / \mathrm{l}$.

Para el estudio urinario, se solicitaron sedimentos, en los que destacaba glucosuria y proteinuria, además de leve leucocituria (1-3/campo de 400 aumentos) y uratos amorfos; no se detectó hematuria ni eosinofiluria. Se decidió completar con el estudio de la función renal de 24 horas, que podía ser compatible con tubulopatía, y mostró proteinuria de $660 \mathrm{mg} / 24 \mathrm{~h}$ y una glucosuria de 1,456 mg/24 $\mathrm{h}$ en una paciente no diabética (Tabla 1). En esos momentos, la creatinina era de $3.17 \mathrm{mg} / \mathrm{dl}$.

\section{Resultados}

Ante un fracaso renal agudo de etiología incierta, con rápida progresión, antes de tener los resultados de las anteriores pruebas complementarias se decide realizar una biopsia renal e iniciar de forma empírica corticoterapia: tres bolos diarios de $500 \mathrm{mg}$ de metilprednisolona, continuando con prednisona oral a dosis de $60 \mathrm{mg}$ diarios. Tras 2 semanas del inicio de corticoterapia, la evolución de la función renal fue favorable, y al momento del alta presentaba una creatinina de $1.76 \mathrm{mg} / \mathrm{dl}$.

Al alta, se recomendó pauta descendente de prednisona oral durante 3 meses, asociada a omeprazol como gastroprotector. Se objetivó una estabilización en la mejoría de la función renal con creatinina de $1.5 \mathrm{mg} / \mathrm{dl}$ a los 10 meses tras el alta de nuestro servicio (Fig. 1). A su vez, la glucosuria desapareció, y la proteinuria disminuyó a $270 \mathrm{mg} / 24 \mathrm{~h}$ a los 4 meses, y con un cociente microalbuminuria/creatininuria de $51.48 \mathrm{mg} / \mathrm{g}$ a los 10 meses. Un año después, la paciente mantenía las mismas cifras de creatinina y microalbuminuria.

Los datos de la biopsia renal fueron concordantes con una ligera nefritis tubulointersticial aguda de probable etiología alérgica, con inmunofluorescencia, inmunohistoquímica y rojo Congo negativos. En las 
Nefro Latinoam. 2020;17

Tabla 1. Función renal de 24 h, compatible con tubulopatía

\begin{tabular}{|c|c|c|c|c|}
\hline & Suero & Orina & Orina 24 h & Rango \\
\hline Creatinina & & $59 \mathrm{mg} / \mathrm{dl}$ & $944 \mathrm{mg} / 24 \mathrm{~h}$ & $(1000-1700 \mathrm{mg} / 24 \mathrm{~h})$ \\
\hline Urea & & $9.64 \mathrm{~g} / \mathrm{l}$ & $15.24 \mathrm{~g} / 24 \mathrm{~h}$ & (13-34 g/24 h) \\
\hline Acido úrico & & $26.2 \mathrm{mg} / \mathrm{dl}$ & $419.2 \mathrm{mg} / 24 \mathrm{~h}$ & $(250-850 \mathrm{mg} / 24 \mathrm{~h})$ \\
\hline Fósforo & & $30.41 \mathrm{mg} / \mathrm{dl}$ & $486.56 \mathrm{mg} / 24 \mathrm{~h}$ & $(300-1200 \mathrm{mg} / 24 \mathrm{~h})$ \\
\hline Glucosa & & $91 \mathrm{mg} / \mathrm{dl}$ & $1456 \mathrm{mg} / 24 \mathrm{~h}$ & \\
\hline Sodio & & $63.9 \mathrm{mEq} / \mathrm{l}$ & $102.24 \mathrm{mEq} / 24 \mathrm{~h}$ & $(50-210 \mathrm{mEq} / 24 \mathrm{~h})$ \\
\hline Potasio & & $21.03 \mathrm{mEq} / \mathrm{l}$ & $33.65 \mathrm{mEq} / 24 \mathrm{~h}$ & $(25-150 \mathrm{mEq} / 24 \mathrm{~h})$ \\
\hline Cloro & & $43.7 \mathrm{mEq} / \mathrm{l}$ & $69.92 \mathrm{mEq} / 24 \mathrm{~h}$ & $(110-250 \mathrm{mEq} / 24 \mathrm{~h})$ \\
\hline Calcio & & $3.01 \mathrm{mg} / \mathrm{dl}$ & $48.16 \mathrm{mg} / 24 \mathrm{~h}$ & $(100-250 \mathrm{mg} / 24 \mathrm{~h})$ \\
\hline Proteínas & & $0.41 \mathrm{~g} / \mathrm{l}$ & $0.66 \mathrm{~g} / 24 \mathrm{~h}$ & $(<0.15 \mathrm{~g} / 24 \mathrm{~h})$ \\
\hline Densidad & & 1.009 & & \\
\hline Osmolalidad & $293 \mathrm{m0sm} / \mathrm{kg}$ & $347 \mathrm{m0sm} / \mathrm{kg}$ & & \\
\hline $\mathrm{pH}$ & & 5.5 & & \\
\hline Volumen orina & & $1600 \mathrm{ml}$ & Peso $61 \mathrm{~kg}$ & Talla $173 \mathrm{~cm}$ \\
\hline $\begin{array}{l}\text { Función glomerular } \\
\text { Aclaramiento } \\
\text { Creatinina } \\
\text { Urea } \\
\text { Fosforo } \\
\text { Calcio }\end{array}$ & & $\begin{array}{l}\text { Valor medio } \\
20.68 \mathrm{ml} / \mathrm{min} \\
10.81 \mathrm{ml} / \mathrm{min} \\
10.06 \mathrm{ml} / \mathrm{min} \\
0.35 \mathrm{ml} / \mathrm{min}\end{array}$ & $\begin{array}{c}\text { Valor a } 1.73 \mathrm{~m}^{2} \\
20.7 \mathrm{ml} / \mathrm{min} \\
11.4 \mathrm{ml} / \mathrm{min} \\
10.06 \mathrm{ml} / \mathrm{min} \\
0.35 \mathrm{ml} / \mathrm{min}\end{array}$ & $\begin{array}{c}\text { Rango a } 1.73 \mathrm{~m}^{2} \\
125 \mathrm{ml} / \mathrm{min} \\
50-75 \mathrm{ml} / \mathrm{min} \\
14 \mathrm{ml} / \mathrm{min} \\
0.5-1.5 \mathrm{ml} / \mathrm{min}\end{array}$ \\
\hline Función tubular: reabsorción & & Valor medio & & Rango \\
\hline Cloro & & $97.61 \%$ & & $98.47 \%$ \\
\hline Sodio & & $97.52 \%$ & & $99.05 \%$ \\
\hline Potasio & & $73.10 \%$ & & $80.02 \%$ \\
\hline Fósforo & & $51.37 \%$ & & $80-84 \%$ \\
\hline Magnesio (0) & & & $3.93 \mathrm{mg} / \mathrm{dl}$ & \\
\hline Magnesio (0 24 h) & & & $62.88 \mathrm{mg} / 24 \mathrm{~h}$ & \\
\hline
\end{tabular}

figuras puede observarse infiltración del intersticio por eosinófilos (Figs. 2-3), con afectación tubular (Fig. 4). Sin embargo, los glomérulos no mostraron alteraciones de interés (Fig. 5).

Tras estos hallazgos anatomopatológicos, con historia clínica compatible y evolución favorable tras corticoterapia, se diagnostica como nefritis tubulointersticial asociada a hipersensibilidad a Anisakis, no habiéndose podido demostrar otra etiología del cuadro.

\section{Discusión}

Nos encontramos ante un caso de nefritis tubulointersticial aguda asociada a hipersensibilidad a
Anisakis tras la ingesta de pescado fresco, con fracaso renal agudo y creatinina pico de $4.67 \mathrm{mg} / \mathrm{dl}$, con biopsia renal compatible con nefritis alérgica con importante presencia de eosinófilos, y buen resultado tras el inicio precoz de tratamiento corticoideo.

Como apoyo al diagnóstico disponemos de datos anatomopatológicos, con biopsia renal que descartó otras posibles patologías, así como datos clínicos, con un antecedente evidente de ingesta de pescado, con el que ya había presentado años antes antecedente de anafilaxia por exposición a Anisakis, y tras el cual empezó el cuadro de deterioro del estado general de la paciente, y la buena respuesta al tratamiento. 


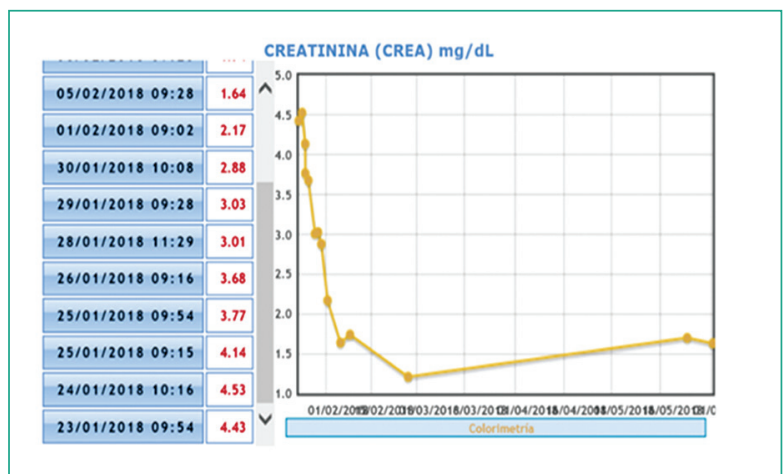

Figura 1. Se muestra la evolución de las cifras de creatinina de la paciente tras la instauración de corticoterapia.

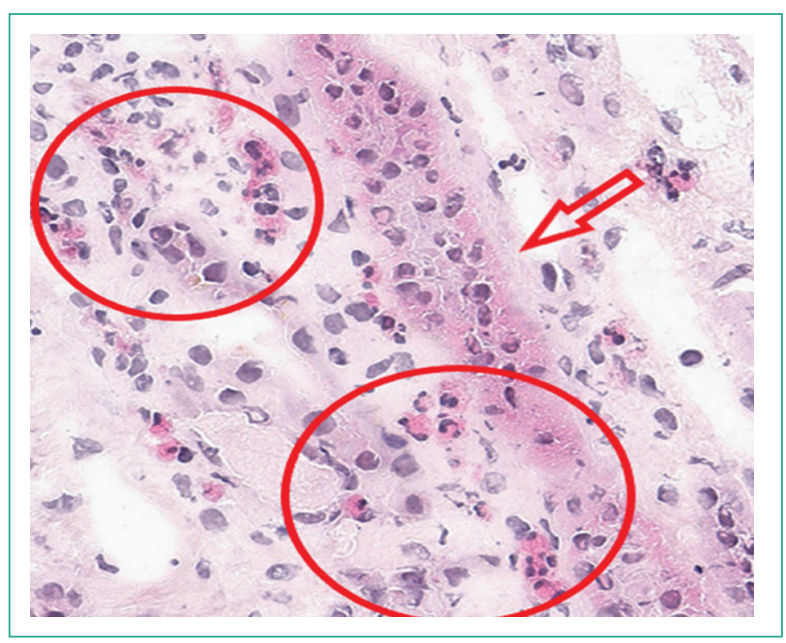

Figura 2. Muestra de anatomía patológica 1. Tinción de hematoxilina eosina: intersticio renal con infiltración de eosinófilos (en circunferencias). Se observa también un túbulo renal (flecha) cortado de forma longitudinal.

Es cierto que, para ser un caso típico, carece de eosinofilia en plasma y eosinofiluria. Por otro lado, aunque el hecho de no haber encontrado en la bibliografía más casos sobre patología renal asociada a Anisakis, excepto un único caso de síndrome nefrótico asociado a alergia a este nematodo ${ }^{4}$, dificulta el diagnóstico, se ha descrito que las nefritis intersticiales agudas pueden poseer componente alérgico 0 de hipersensibilidad, especialmente las asociadas a fárma$\cos ^{5,6}$ e infecciones, que provocarían una reacción inmunitaria tras el depósito intersticial de «antígenos plantados" ${ }^{6}$. Además, en cuanto al Anisakis, es bien conocido su potencial alergénico, y se sabe que las larvas pueden llegar hasta el intestino delgado, atravesar la mucosa y provocar granulomas eosinófilos, y los síntomas aparecen entre 1 y 2 semanas tras la

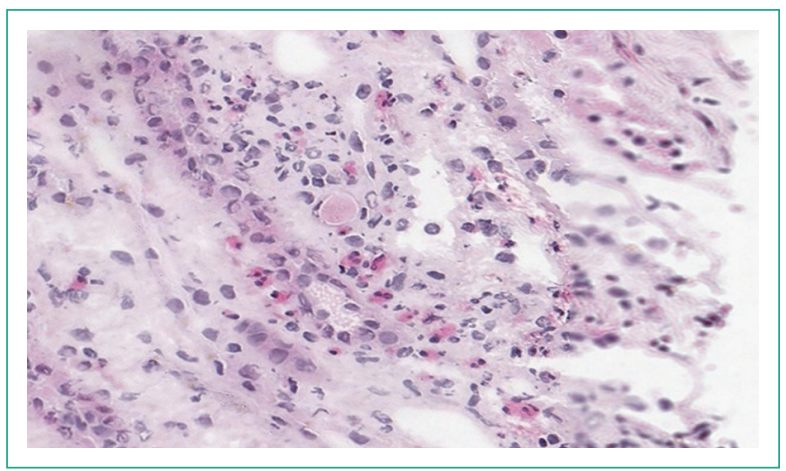

Figura 3. Muestra de anatomía patológica 2. Tinción de hematoxilina eosina: intersticio renal con infiltración de eosinófilos.

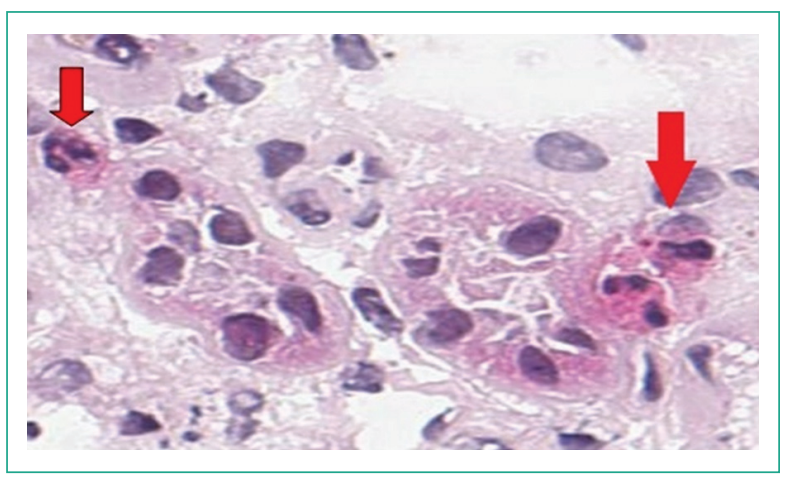

Figura 4. Muestra de anatomía patológica 3. Tinción hematoxilina eosina: eosinófilos (flechas) infiltrado túbulos renales.

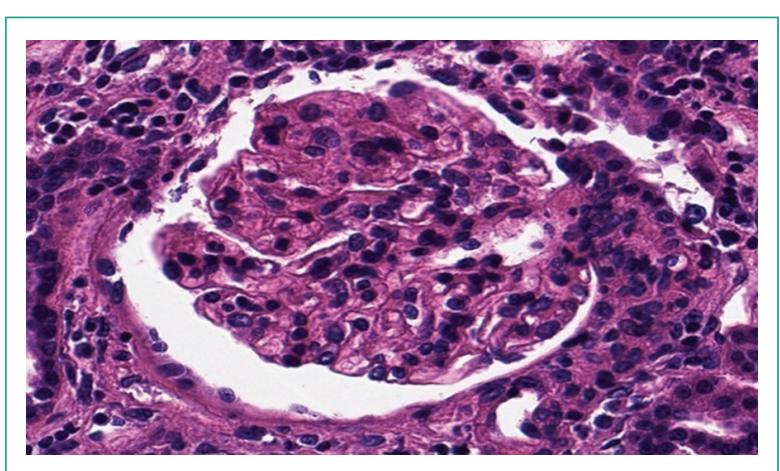

Figura 5. Muestra de anatomía patológica 4. Tinción hematoxilina eosina: glomérulo renal sin alteraciones de interés.

exposición, y con clínica de dolor abdominal intermitente, clínica digestiva y fiebre ${ }^{1}$, similar a la que presentó nuestra paciente. 
De este modo, con un antecedente de exposición al antígeno frente al que existe sensibilización, con evolución clínica y analítica y estudio anatomopatológico compatibles, sin haber encontrado otro posible desencadenante para esta nefritis, se consideró como diagnóstico etiológico la hipersensibilidad a Anisakis como causante de la nefritis tubulointersticial aguda.

Así, sería este el segundo caso documentado que asociaría la hipersensibilidad a Anisakis con afectación renal, y el primer caso de nefritis tubulointersticial asociado a Anisakis, por lo que consideramos importante darlo a conocer para que se tenga en cuenta en posteriores diagnósticos diferenciales, habida cuenta de la alta prevalencia de hipersensibilidad a Anisakis.

\section{Conclusión}

A pesar de la dificultad diagnóstica por no existir ningún caso previo, consideramos que en este existen motivos suficientes para asegurar que se trata de un caso de nefritis tubulointersticial asociado a hipersensibilidad a Anisakis, y concuerdan con el diagnóstico la presentación clínica y la biopsia renal. Dado que se trata este del primer caso documentado, consideramos oportuno darlo a conocer para facilitar posteriores diagnósticos.

\section{Financiación}

Los autores declaran no haber recibido financiación alguna para la publicación del caso clínico.

\section{Conflicto de intereses}

Los autores declaran no tener conflicto de intereses.

\section{Responsabilidades éticas}

Protección de personas y animales. Los autores declaran que para esta investigación no se han realizado experimentos en seres humanos ni en animales.

Confidencialidad de los datos. Los autores declaran que han seguido los protocolos de su centro de trabajo sobre la publicación de datos de pacientes.

Derecho a la privacidad y consentimiento informado. Los autores declaran que en este artículo no aparecen datos de pacientes.

\section{Bibliografía}

1. Weiler PF, Nutman TB. Nematodos intestinales. En: Harrisons. Principles of internal medicine. (Internet). 17 ${ }^{\mathrm{a}}$ ed. España: McGraw-Hill/Interamericana; 2012 p. 1319-23. Disponible en: https://es.slideshare.net/reyesalberto353/medicina-interna-de-harrison-17-edicion-vol-1

2. Mas Capó J, Muñoz Gutiérrez J. Filariasis e infecciones relacionadas. Otras infecciones causadas por nematodos tisulares. En: Farreras/

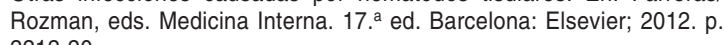
2212-20.

3. Aibinu IE, Smooker PM, Lopata AL. Nematodos Anisakis en peces y mariscos: desde la infección hasta las alergias. Int J Parasitol Parásitos Wildl. 2019;9:384-93.

4. Meseguer J, Navarro V, Sánchez-Guerrero I, Bartolomé B Negro Alvarez JM. Anisakis simplex allergy and nephrotic syndrome. Allergol Immunopathol (Madr). 2007;35(5):216-20.

5. Kshirsagar AV, Falk RJ. Tratamiento de la nefritis intersticial aguda. (Internet). Uptodate. Paul M Palevsky, ed. Julio 2019 (consultado en agosto 2019). Disponible en: https://www-uptodate-com.ar-bvsalud.a17. csinet.es/contents/treatment-of-acute-interstitial-nephritis?search=nefritis\%20al\%C3\%A9rgica\&source=search_result\&selectedTitle=1 150\&usage_type=default\&display_rank=1

6. González Monte, E. Nefropatías intersticiales. En: Hernando. Nefrología clínica. 4. ${ }^{a}$ ed. Madrid: Editorial Panamericana; 2014. p. 625-35. 